\title{
A CONCEPÇÃO DE SUBLIMAÇÃO NO TRABALHO DE JEAN LAPLANCHE¹
}

\author{
Érico Bruno Viana Campos² \\ Universidade Estadual Paulista Júlio de Mesquita, Bauru-SP, Brasil
}

\begin{abstract}
RESUMO. A teoria da sedução generalizada é uma proposta de novos fundamentos para a psicanálise que promove um reposicionamento metapsicológico crucial, por resgatar o papel fundamental do outro na constituição da subjetividade. $\mathrm{O}$ objetivo deste ensaio é apresentar e discutir a concepção de sublimação neste referencial, trabalhando as dificuldades e limitações de uma noção estrita em que o conceito aparece como mera modificação do objeto e da meta da pulsão sexual. Pretende-se discutir as limitações dessa concepção na sua tarefa de articular a subjetividade individual com a organização cultural, indicando a proposta de Jean Laplanche de uma sublimação originária e de uma neoformação da pulsão como tentativas de superar alguns desses impasses teórico-conceituais. Concluímos que essa proposta laplanchiana é insuficiente para dar conta das limitações das teorias das pulsões e da cultura em psicanálise, que são um problema ainda atual e pertinente nesse campo de estudos.
\end{abstract}

Palavras-chave: Sublimação; teoria da sedução generalizada; Laplanche, Jean (1924-2012).

\section{THE CONCEPT OF SUBLIMATION IN JEAN LAPLANCHE'S WORK}

\begin{abstract}
The theory of generalized seduction is a proposal for a new foundation to psychoanalysis that promotes a crucial metapsychological repositioning to rescue the other's role in subjectivity constituyion. The aim of this paper is to present and to discuss the concept of sublimation in this reference, working difficulties and limitations of a strict notion in which the concept appears as a mere modification of the object and the target of sexual drive. It is intended to discuss the limitations of this conception in its task of articulation between the individual subjectivity and the cultural organization, indicating the proposal of Jean Laplanche for originary sublimation and neoformation of drive, as attempts to overcome some of these theoretical and conceptual impasses. We conclude that Laplanche's proposal is insufficient to account for the limitations in the theories of drives and culture in psychoanalysis, therefore, that it is a problem still current and relevant in this field of studies
\end{abstract}

Key words: Sublimation; generalized seduction theory; Laplanche, Jean (1924-2012).

\section{LA CONCEPCIÓN DE SUBLIMACIÓN EN EL TRABAJO DE JEAN LAPLANCHE}

RESUMEN. La teoría de la seducción generalizada es una propuesta de nuevos fundamentos para el psicoanálisis que promueve un reposicionamiento metapsicológico crucial al rescatar el papel fundamental del otro en la constitución de la subjetividad. El objetivo de este ensayo es presentar y discutir la concepción de sublimación en este referencial, trabajando las dificultades y limitaciones de una noción estricta en que el concepto aparece como una mera modificación del objeto y de la meta de la pulsión sexual. Se pretende discutir las limitaciones de esta concepción en su tarea de articulación entre la subjetividad individual y la organización cultural, indicando la propuesta de Jean Laplanche de una sublimación originaria y de una neoformación de la pulsión, como intentos de superación de algunos de estos obstáculos teóricosconceptuales. Se concluye que esta propuesta laplanchiana es insuficiente para dar cuenta de las limitaciones en las teorías de las pulsiones y de la cultura en psicoanálisis, siendo esta, por lo tanto, una problemática aun actual y pertinente en este campo de estudios.

Palabras-clave: Sublimación; teoría de la seducción generalizada; Laplanche, Jean (1924-2012)..

1 Este artigo é oriundo da Comunicação oral apresentada na Mesa-Redonda "Nas Vias da Sublimação: Psicanálise e Criação" do I Encontro Brasileiro de Psicanálise e Sedução Generalizada realizado na Universidade Estadual de Maringá (UEM) em Abril de 2012.

2 Endereço para correspondência: Av. Eng. Luiz Edmundo Carrijo Coube, 14-01, CEP 17.033-360, Bauru-SP. E-mail: ebcampos.online@gmail.com 
Este artigo pretende discutir o conceito de psicanalítico de sublimação tomando-se como fio de argumentação as proposições de Jean Laplanche sobre essa problemática no pensamento freudiano em particular, e na teoria psicanalítica, em geral. Trata-se de uma apresentação que se insere em um plano de pesquisas mais abrangente sobre a sublimação e a teoria da cultura em psicanálise e que tem como objetivo não só problematizar alguns lugares-comuns da teoria da sublimação, mas também demarcar os direcionamentos propostos pelo autor em sua interpretação dos textos freudianos, entendendo que esse autor constitui referência fundamental em qualquer discussão dos fundamentos da teoria psicanalítica. Nesse intuito, apresentaremos e discutiremos o texto clássico do pensamento do autor sobre o tema, que congrega seus dois cursos sobre a sublimação ministrados na Unidade de Ensino e Pesquisa em Ciências Humanas Clínicas da Sorbonne (Universidade de Paris VII) entre os anos de 1975 e 1977, e que foi publicado no terceiro volume de suas Problemáticas (Laplanche, 1989). O recurso a Laplanche é um meio em direção a uma meta mais geral que poderia ser resumida como o trabalho de fundamentação de uma teoria da cultura a partir do conceito de sublimação, entendido como operador ou articulador de uma série de passagens essenciais em psicanálise, como natureza/cultura, indivíduo/sociedade, não sexual/sexual, tanático/erótico, repetição/criação, que convergem para uma renovação da concepção de sujeito em psicanálise e mesmo para uma ética da psicanálise.

O que dizer da sublimação? De saída, podemos dizer que a sublimação é um conceito simultaneamente fundamental e superficial em psicanálise, uma vez que ele está em tantos lugares (na teoria pulsional, na teoria da defesa, na teoria da cultura e até mesmo na teoria da técnica), mas não é sistematizado e apresentado em lugar nenhum. Para ser honestos, podemos afirmar que a teoria da sublimação é algo que Freud deixou por fazer; no entanto essa concepção está operante ao longo de toda a obra freudiana, inclusive passa por uma série de modificações e ressignificações que não são suficientemente esclarecidas e elaboradas. Ela é, como bem aponta Laplanche (1989), uma cruz no pensamento freudiano: não apenas no sentido de um fardo difícil de carregar, mas também no de uma encruzilhada em que se encontram a teoria, a clínica e a cultura, porque a sublimação é, não só, mas também um destino pulsional, um mecanismo de defesa, um objeto e/ou um ideal culturalmente valorizado, e, além de tudo, um parâmetro de cura. Curiosamente, o peso teórico-conceitual dessa concepção contrasta com a sua característica descritiva mais essencial e pungente: a sua condição etérea, "sublime" e inefável.

Nesse sentido, a sublimação é representativa daquilo que escapa a qualquer representação teorética e aos diversos morfismos (Laplanche, 1992) que utilizamos para recobrir o objeto da psicanálise: os modelos físicos, biológicos, psicológicos, sociológicos e assim por diante, que constituem o estofo do movimento teorizante do campo psicanalítico. Destarte, é mais um índice daquilo que é intangível e que aponta para a "coisa" psicanalítica, para utilizar a consagrada expressão lacaniana; ou, para ficarmos mais próximos do pensamento laplanchiano, o excesso traumático que incide sobre o corpo como um apelo enigmático, disparando o circuito pulsional.

Esse tipo de posição sintética e generalizante, quase expressão de uma "visão de mundo", nos termos clássicos freudianos, é, inclusive, o ponto de chegada das discussões sobre o tema no campo psicanalítico contemporâneo, mas, infelizmente, esse conceito é muitas vezes tomado como um mero postulado, ou pior, como pura justificativa ideológica. $O$ que falta é justamente problematizar essa caixa de pandora, e é isso que Laplanche propõe ao longo dos cursos que vamos tentar apresentar e discutir.

\section{Situação e Derivação da Sublimação}

O livro de Laplanche está organizado em duas partes, que refletem a divisão dos cursos. $\mathrm{Na}$ primeira parte, intitulada "Para situar a sublimação", o autor faz uma grande contextualização da sublimação na obra de Freud e no seu próprio percurso ao longo da série de cursos que constituíram as "Problemáticas". Mais especificamente, apresenta e desenvolve os aspectos implícitos na definição clássica do conceito em sua articulação com a teoria pulsional, especialmente no contexto da primeira teoria das pulsões, tomando como eixo o estudo da lembrança de infância de Leonardo da Vinci (Freud, 1910/1996). Já a segunda parte avança na 
discussão da sublimação para além do seu enraizamento na teoria das pulsões como uma modalidade específica de destino pulsional e desenvolve a sua relação com a teoria da cultura. Apresenta a concepção de uma sublimação que não é apenas destino do desejo do sujeito em direção aos ideais culturais, mas um processo originário, que está na origem da própria civilização. Nessa parte, a discussão não só avança para a dimensão cultural, mas também rearticula a discussão com o segundo dualismo pulsional. O texto que servirá de eixo norteador será o curto e por vezes subdimensionado estudo sobre a aquisição e o controle do fogo (Freud, 1931/1996).

Um aspecto importante dessa proposta é sua articulação com o curso precedente do autor, que trata das castrações e simbolizações (Laplanche, 1988). Naquele outro percurso, o autor se preocupara em fazer uma discussão mais ampliada dos processos de simbolização a partir dos rituais culturais em torno da castração. Sua proposta é sair do escopo puramente metapsicológico da teoria da castração e de sua lógica fálica, para descrever a estrutura e o tipo de simbolização que ocorre nesses rituais. Nesse percurso, o autor descobre que as simbolizações rituais - portanto, também o tipo de apoio à elaboração simbólica que as culturas oferecem, e mesmo os ideais culturais fornecidos como destino sublimatório - têm características muito específicas, que se assemelham a própria estrutura da fantasia do ponto de vista psicanalítico. A referência aqui é o clássico texto de Laplanche e Pontalis (1988) sobre as fantasias originárias e as origens da fantasia, onde é proposta a concepção da fantasia como um roteiro de múltiplas entradas, em que a posição de sujeito se dissemina nas diversas posições do enredo imaginário como resultado das leis do processo primário. Tratase, portanto, de uma estrutura formal complexa, marcada pela ambiguidade e pela contradição. Pois bem, em seu estudo dos rituais culturais de castração, o autor encontra a mesma estrutura polissêmica e ambígua de simbolização. Dessa constatação ele retira uma indicação importante: os rituais culturais permitem, com sua estrutura polissêmica, um tipo de identificação que não é simplesmente um ideal socialmente valorizado que venha a acolher a fantasia de castração do indivíduo, mas um verdadeiro processo coletivo que permite a elaboração dessa fantasia individual e possibilita a criação de novos símbolos. Haveria, então, algo nos processos de simbolização conduzidos na cultura que permitiria uma elaboração do novo e uma criatividade, que romperia com a visão, tradicional em psicanálise, da repetição do passado no presente e do desejo do indivíduo no plano da cultura. Este ponto nos parece crucial e é o verdadeiro mote do curso sobre sublimação, já que a mesma questão se aplica ao problema da sublimação. Isso quer dizer que é com esse questionamento em mente que devemos abordar a problemática da sublimação.

Laplanche, nesse curso, situa a sublimação a partir do resgate da definição sintética e clássica apresentada no vocabulário de psicanálise:

Processo postulado por $\begin{gathered}\text { Freud para } \\ \text { atividades humanas }\end{gathered}$
explicar com a
aparentemente sem relação com
sexualidade, mas que encontrariam sua
origem na força da pulsão sexual. Freud
descreveu como atividade de sublimação
principalmente a atividade artística e a
investigação intelectual. Diz-se que uma
pulsão foi sublimada na medida em que
ela é desviada para uma nova meta não
sexual e visa a objetos socialmente
valorizados. (Laplanche \& Pontalis,
1998, p. 638)

Estão aí todas as características fundamentais que balizam o conceito, em especial um duplo aspecto: por um lado, o metapsicológico, pois envolve a passagem do sexual ao não sexual por meio de uma modificação da meta, e, por outro, aquele referente à teoria da cultura, na medida em que envolve a passagem do indivíduo à sociedade por conta do destino socialmente valorizado por meio de uma modificação do objeto. Essa dimensão cultural, por sua vez, indica um aspecto ético, já que a definição do objeto socialmente valorizado depende de um juízo de valor, que pode ser moral, epistêmico ou ético. Assim, a questão que a sublimação colocaria "é uma metapsicologia e, paralelamente a essa metapsicologia, uma teoria dos valores" (Laplanche, 1989, p. 12).

Não obstante, examinando as características da pulsão e seus destinos no tocante à sublimação, chegamos a uma conclusão alarmante, pois a sublimação constituiria um processo de total descaracterização da pulsão sexual, já que envolveria uma mudança de fonte, de meta, de objeto, de forma que nada restaria 
da sexualidade no objeto sublimado (Laplanche, 1989).

Para dar conta desses paradoxos, Laplanche propõe um amplo resgate da análise do texto de Freud sobre Leonardo da Vinci, em que sobressai justamente a possibilidade de a sublimação ser um destino da pulsão que se diferencia da inibição egoica e da repetição sintomática. Seria então uma terceira possibilidade, que se descolaria parcialmente do recalque e possibilitaria efetivamente algo da ordem da criação.

Outro caminho de argumentação é o resgate da primeira teoria das pulsões, esclarecendo as relações entre as pulsões de autoconservação e as pulsões sexuais. Nesse momento, 0 autor resgata sua interpretação da relação entre sexualidade e autoconservação, defendendo sua suficientemente conhecida proposição revisionista de que toda pulsão é sexual e que as funções de autoconservação seriam o que forneceria o apoio para o desenvolvimento das pulsões sexuais de vida e de morte. O que há de particularmente novo e interessante nessa apresentação é a exposição do que o autor denomina de modelo da charneira: uma articulação vicariante entre os dois planos da economia psíquica. Trata-se de uma metáfora para explicar as relações vicariantes entre as funções de autoconservação e as pulsões sexuais:

Chegamos, portanto, a essa linha do apoio, a essa charneira que articula os dois planos um sobre o outro. O apoio consiste no fato de que os dois tipos de pulsões ou os dois modos de funcionamento se apoiam um no outro, mas numa mesma atividade. (Laplanche, 1989 , p. 43, grifo do autor).

A ideia fundamental nesse modelo é que essas atividades são complementares e mutuamente incidentes, daí a concepção de uma articulação entre dois planos que a noção de dobradiça sugere. No que tange ao problema da sublimação, que é o que nos interessa, Laplanche faz uma proposição interessante: entender a sublimação como um mecanismo recíproco ao mecanismo de apoio - ou seja, se o apoio é o que permite a transição das atividades psíquicas das funções de autoconservação para as pulsões sexuais, a sublimação é o que permite a retroação do campo pulsional sobre a autoconservação. Nas palavras do autor:
Assim, a sublimação só se compreende no âmbito dessa relação geral entre os dois planos, tal como foi desenvolvida pela teoria do apoio. Mas, na sublimação, não haveria somente influência recíproca, indução de um plano para o outro, mas uma verdadeira derivação, uma verdadeira drenagem inversa daquela de que falamos mais acima, drenagem ao revés da energia sexual para a não-sexual. (Laplanche, 1989, p. 56)

O autor propõe, ainda, que essa retroação da sexualidade sobre o corpo incidiria de forma traumática sobre o campo não sexual, possibilitando o que denomina de neoformação da pulsão. Os limites da exposição não permitem apresentar todo o argumento que sustenta a proposta, mas a base é simples: se o apoio é o que permite a passagem do não sexual ao sexual, a sublimação, na medida em que opera a passagem do sexual ao não sexual, é o mecanismo de retroação da sexualidade sobre o corpo. Assim, por vias distintas, chegamos ao mesmo ponto de convergência: a possiblidade de criação do novo por meio da sublimação tanto no nível do desejo individual quanto nas formações coletivas. Porém, essa criação do novo não é secundária ao desenvolvimento da personalidade, ela é concomitante a ele e deve ser referida a uma dimensão de criação da via sublimatória do desejo para a pessoa que está presente desde as origens. Desse modo, Laplanche resgata a dimensão propriamente originária da sublimação. Segue a passagem crucial:

Se mantivermos a ideia de que a sublimação está muito próxima do apoio, convirá, sem dúvida, atribuir uma significação especial a estas palavras: 'desde a origem'. A sublimação não seria uma reversão, uma segunda reversão em relação ao primeiro tempo do nascimento do sexual: apoio e sublimação, de uma certa forma, andariam, ao contrário, emparelhados. Há 'desde a origem', uma espécie de ajuntamento quando uma sublimação ocorre. As verdadeiras sublimações são 'precoces', como Freud nos deu a entender, especialmente a propósito dessa sublimação particularmente sólida que é a intelectualidade de Leonardo. Creio que seria necessário conceber a sublimação como algo que se produz no próprio momento do surgimento da 
excitação sexual, no tempo da pulsão parcial sexual. Mas esse termo 'precoces' implica uma significação temporal, cronológica, a qual ameaça impor a ideia de que só existem sublimações nos primeiros anos de vida. Não existem possibilidades, mesmo que sejam raras, de uma sublimação 'tardia' e, em particular, será preciso abandonar a ideia de uma sublimação que se produza durante a cura analítica? Se substituo a qualificação de 'precoce' pela de 'originária', é para deixar bem claro que o originário não é monopólio dos anos de origem. É preciso admitir então que a ideia de que a pulsão sexual não é dada de uma vez por todas mas, levando verdadeiramente essa teoria de Freud a sério, que há capacidade no ser de criar sem cessar, perto da origem, o sexual, a partir de toda espécie de abalos exteriores, a partir do novo, em relação ao qual o trauma representa apenas o mais dramático paradigma. (Laplanche, 1989 , p. 91 , grifo do autor)

Com isso Laplanche arma um caminho completamente distinto para a problemática da sublimação, pois inverte a questão clássica, colocando que a sublimação estaria dada, de alguma forma, desde as origens e não seria uma transposição última no arco libidinal; portanto a sublimação seria um mecanismo originário, ligado ao traumatismo e ao enigma próprio da concepção de originário que é característica da teoria da sedução generalizada. Em termos teóricos, a sublimação seria então uma forma de derivação no circuito pulsional.

Esse conceito de derivação, por sua vez, é uma metáfora do que em matemática se chama de operações de derivação (equações derivadas) que Laplanche (1985) utiliza para pensar essas passagens entre os diversos níveis da teoria e do circuito pulsional (autoconservação/sexualidade, morte/vida).

Embora seja bastante interessante e instigante, boa parte desse primeiro curso é voltada para essa discussão metapsicológica, embora apoiada em um estudo de psicanálise aplicada, de forma que a discussão sobre o campo propriamente da cultura é levada para a segunda parte. De qualquer forma, nessa primeira parte o fio condutor não se perde: a sublimação seria uma possibilidade de criação do novo.

A segunda parte se volta para uma extensa análise do texto sobre a aquisição e o controle do fogo de Freud, que, por sua vez, está assentado na análise do mito grego de Prometeu, que, como se sabe, roubou o fogo dos deuses e o entregou para os homens, sendo por isso condenado a ficar acorrentado a um rochedo e ter seu fígado comido pelos abutres por toda a eternidade. Novamente, não vamos ter condições de acompanhar a extensa discussão de Laplanche sobre o tema, a qual é bastante rica e ampla, mas vamos reter o fundamental.

O fundamental da interpretação de Freud é que esse mito expressa a fantasia da origem da cultura por meio da renúncia pulsional, já que o controle do fogo só pode ser alcançado pela renúncia do homem a extingui-lo com sua própria urina. Laplanche aponta dois aspectos importantes nesse percurso. O primeiro é o resgatado erotismo uretral como componente pulsional essencial no domínio do fogo e, por consequência, na base de todo o processo civilizatório. Já o segundo é que, por essa via se reencontra o tema da neogênese da pulsão. A passagem que sintetiza esse percurso é a seguinte:

O artigo de Freud, 'A conquista do fogo', está longe de ter esgotado o interesse que se possa dedicar à questão do fogo e à interligação destes dois temas: fogo e sublimação. De modo que, antes de enveradar por outros caminhos, gostaria, ainda a propósito desse artigo, de insistir em duas sugestões, advertências ou admoestações, que acreditamos ter encontrado nele: por um lado, descortinamos o fato de que um avatar libidinal preciso está ligado ao fogo: o erotismo uretral. Mas, para além desse avatar, a advertência é a seguinte: é o caráter essencial, como fundamento de todo simbolismo e de toda a simbolização, da relação com o corpo; não do corpo em geral nem na sua totalidade, mas a relação com zonas precisas, zonas de passagem, zonas erógenas, como lugares sobre os quais nos perguntamos se não serão os pontos de amarração de todo o apoio, de toda a emergência libidinal. É verdade que procuramos a sublimação no caminho de uma espécie de neogênese contínua da sexualidade, talvez de um certo reexame do princípio da constância das quantidades de excitação; não, evidentemente, no sentido de um reexame do princípio fisiológico da homeostase mas, ao nível libidinal, do 
reexame da ideia de que a soma libidinal pulsional seria um dado definitivo nãomodificável e como que naturalmente dado. Pois bem: somos advertidos por esse artigo que, se existe neogênese, esta deve ser concebida como tendo seu ponto de apoio (qualquer?) no organismo. (Laplanche, 1989, p. 159)

Observa-se que a análise do artigo sobre o controle do fogo caminha na mesma direção de argumentação da análise do texto sobre Leonardo da Vinci: um caminho alternativo à inibição e ao recalque que se constitui originariamente e se mantém como um processo criador de novas pressões pulsionais por meio da elaboração do impacto do trauma. Trata-se, assim, de um mecanismo de origem da pulsão e também de um destino, já que se trata da retroação da sexualidade sobre o corpo e, além disso, sobre a cultura. A questão que permanece é se o destino final da moção sublimada também é criativa, no sentido de engendrar novos circuitos simbólicos e escapar da mera repetição da fantasia de desejo a que se atrelou em sua organização. Laplanche também se pronuncia sobre essa dupla possibilidade, a saber, os caminhos da defesa e repetição ou o caminho propriamente criativo e menos vinculado ao recalque, mais próximo de uma derivação do id em ego na conquista da cultura. $O$ argumento, nesse ponto, é baseado no contraste entre o mito de Prometeu, que seria um herói da renúncia, e o mito de Hércules, que seria propriamente um herói "libidinal". Explicando melhor: enquanto Prometeu consegue alçar à civilização por meio de recursos defensivos próximos ao recalque, Hércules conseguiria uma via de satisfação pulsional mais direta de sua libido em direção à cultura. Aqui a análise de Laplanche reencontra o mote apresentado a respeito da sublimação em Leonardo da Vinci, ou seja, a sublimação como um destino distinto de um mero processo defensivo capaz de engendrar a formação de novas articulações simbólicas que encontram respaldo na cultura, renovando-a.

Após essa segunda análise, Laplanche se volta para o reexame do problema do traumatismo, compreendido agora a partir de uma ultrapassagem dos dualismos mente $x$ corpo e sexual $x$ não sexual permitida pelo exame da problemática da sublimação. Assim entendido, o traumatismo corresponde aos entraves e pressões da energia sexual em sua busca por significação, ocasionando falhas de tradução nessa passagem. Afirma o autor:

Assim, o problema do traumatismo não é posto em termos de repercussão de um abalo físico sobre o espírito, mas como passagem de uma energia para outra, como produção (a cujo respeito deixo em aberto a questão de saber se é um reprodução ou uma neoprodução) de uma energia que funciona segundo um novo regime: a energia sexual. (Laplanche, 1989, p. 171)

Embora sejam muito interessantes as considerações que se seguem sobre 0 traumatismo na origem da vida psíquica, elas pouco avançam na compreensão do problema específico da sublimação, pois nada mais fazem do que reiterar a posição fundamental da teoria da sedução generalizada, a saber, o lugar do outro na constituição traumática da fonte pulsional. O que se nota é um retorno à problemática do originário e da metapsicologia das pulsões, sem que se chegue efetivamente a uma discussão da outra extremidade do problema: a cultura. Parece-nos que essa é inclusive, a tônica até o desfecho da segunda parte do livro de Laplanche, de forma que a derivação da teoria da sublimação para o plano da cultura não é propriamente contemplada; mas vejamos antes a que conclusão chega o autor.

$\mathrm{Na}$ sequência, Laplanche passa a discorrer sobre a singularidade da concepção de sexualidade em psicanálise, que envolve tanto uma especificidade quanto um alargamento do sexual, encontrando em uma metáfora energética seu fundamento conceitual. A natureza dessa energia é então discutida, defendendo que se devem ultrapassar os modelos fisicalistas e biológicos para encontrar na radicalidade do conceito de pulsão de morte o fundamento propriamente traumático de toda a teoria das pulsões. No âmbito do comentário sobre o livro de um comentador da obra de Leonardo da Vinci, o autor chega a algumas considerações interessantes sobre os processos de sublimação na obra de arte. Em especial, ele destaca a necessidade de diferenciar um modo de simbolização próprio ao processo de criação artística, diferente da mera defesa:

De fato, deveríamos conceber a elaboração artística, essa elaboração no desenho ..., como elaboração ao mesmo tempo do ataque interno e do ataque 
externo, do que Freud chama a excitação e do que chama ou do que se traduz por estímulo .... Pois bem, poderse-ia dizer que a simbolização na obra de arte desfaz essa distinção, desfaz até a relação metafórica entre o externo e o interno. Ela reúne o externo e o interno para retomá-los num outro nível de símbolo. (Laplanche, 1989, p. 189-190, grifos do autor).

Tem-se aqui a afirmação de uma especificidade dos processos sublimatórios na criação da obra de arte que se aproxima, novamente, da elaboração do traumático em uma forma de simbolização com características específicas da fantasia originária e dos rituais culturais. Por fim, toda essa problemática é resumida em uma fórmula enigmática e ambígua referente à expressividade singular da obra de arte, em que essa dupla dimensão traumática é simbolizada: a "projeção narcísica da destruição do narcisismo" (Laplanche, 1989, p. 195).

Depois dessas indicações preciosas, Laplanche retorna à discussão mais propriamente metapsicológica, recaindo na especulação freudiana do "além do princípio de prazer" para daí retirar um modelo ampliado do aparelho psíquico. Trata-se de uma nova derivação do modelo da tina, dessa vez afirmando a tangência entre unidade do organismo e unidade do ego, em que a pulsão aparece como o duplo limite traumático simultaneamente externo e interno. Como esses desdobramentos finais não interessam tanto à problemática específica da sublimação, a não ser para ilustrar a riqueza e a ambiguidade entre a dimensão interna e a dimensão externa do traumatismo pulsional, podemos afirmar que todo esse percurso final de discussão da teoria pulsional dirige-se para a sustentação da hipótese da sublimação originária como paradigma traumático da criação da pulsão.

\section{DISCUSSÃO}

O que podemos dizer ao final dessas considerações sobre a obra de Laplanche? Parece-nos que discussão sobre a distinção entre o sexual e o não sexual foi suficientemente trabalhada, apontando algumas resoluções interessantes. Como se sabe, essa definição sobre a transformação do sexual em não sexual sempre foi entendida de forma muito restritiva e tendeu a ser deixada de lado com o advento da segunda teoria das pulsões. Afinal, a própria distinção entre sexual e autoconservativo se perde sob a denominação mais ampla de pulsões de vida. Com isso também a própria dimensão do organismo tende a sucumbir à teoria psicanalítica. Ao reposicionar os termos na teoria das pulsões, marcando a distinção entre funções de autoconservação e pulsões sexuais de vida e de morte, Laplanche resgata a tensão entre sexualidade e organismo. Sua hipótese da reversibilidade entre apoio e sublimação por meio do modelo da charneira vem resgatar a importância dessa dimensão "não sexual" em psicanálise, renovando a discussão para incluir as atividades somáticas no circuito mais amplo da vida psíquica. Podemos entender, assim, que esta é uma grande contribuição de Laplanche para a discussão da teoria da sublimação. Ainda no plano da discussão
metapsicológica, duas questões são trabalhadas. A primeira é a independência da sublimação em relação ao recalque e à defesa. Nesse âmbito, o argumento é muitas vezes abordado, mas não avança muito. $\mathrm{O}$ autor se preocupa em distinguir algumas nuanças, como os diferentes tipos de defesa (recalque, repressão) e os diversos níveis da renúncia ao desejo (âmbito do sujeito ou da sociedade), tendendo a afirmar que a sublimação estaria em última instância, articulada à lógica do recalque, uma vez que esse seria responsável pela metaforização simbólica. A questão seria o grau de liberdade ou de independência que a sublimação ganharia em relação aos conteúdos sexuais e processos repetitivos (fantasias) do sujeito. Entra-se aí propriamente no mérito da segunda questão, que é o potencial criativo da sublimação; mas, a esse respeito, as questões não se elucidam tanto. $O$ autor chega a sintetizar a sua posição sobre isto propondo balizas para a derivação da sublimação, que seriam (Laplanche, 1989, p. 211-212):

1. O destino pulsional deve ser pensado como um entrelaçamento desde a origem entre o não sexual e a fonte permanente do sexual;

2. Essa fonte permanente implica a ideia de uma neocriação repetida e continuada de energia sexual;

3. A neocriação da sexualidade que se articula no processo criativo está intimamente ligada à questão do traumatismo; 
4. A discussão sobre a sublimação é inseparável da própria concepção geral da psicanálise e de seu momento histórico.

Nesse último aspecto é que aparece mais claramente uma posição quanto ao lugar do conceito de sublimação em uma concepção geral do que seja o campo da psicanálise, defendendo que a sublimação deve transcender uma dimensão puramente técnica e clínica para ser um elemento de reflexão sobre a subjetividade e a cultura:

\begin{abstract}
Pois bem, eu penso que não é assim que as coisas devem ser concebidas, que a psicanálise não é uma técnica limitada, ainda que seja uma técnica deveras apreciável de "mudança" individual, mas que talvez ela própria introduza um elemento de derivação, de deriva, algo que mexe não somente com a nossa concepção da sublimação, mas com a própria sublimação no movimento cultural. (Laplanche, 1989, p. 212)
\end{abstract}

O que nos parece uma grande limitação deste trabalho de Laplanche é que a discussão nunca entra exatamente na dimensão da cultura. Ela está sempre como um horizonte externo à discussão, que é fundamentalmente metapsicológica, principalmente no âmbito da teoria pulsional. Não há uma discussão sobre o que constitui a cultura enquanto sistema simbólico próprio e como essas representações influenciam a criação do circuito pulsional, pois tanto no momento propriamente originário e traumático quanto nos momentos posteriores da estruturação da personalidade os movimentos de transposição de regimes pulsionais estão atrelados a dinâmicas relacionais com os objetos, por meio de processos identificatórios.

A questão é que, curiosamente, Laplanche não explora essa dimensão do problema. Mesmo na sua síntese sobre o processo de criação de destinos pulsionais sublimatórios, o autor não avança além de algumas indicações, como, por exemplo, a de que a ligação é o que estaria em jogo na elaboração do traumatismo em sua dimensão originária, de tal forma que seria necessário conceber diferentes níveis de ligação e elaboração simbólica da pulsão, que não deveriam se restringir apenas ao esquema clássico ligação narcísica - elaboração simbólica.
Ora, toda a questão da sublimação passaria justamente por sair dessa discussão exclusivamente originária, para pensar as diferentes nuanças que o processo admite em diversos momentos de organização da personalidade. No âmbito da própria teoria pulsional, caberia tentar entender os níveis de produção de pulsão, se no âmbito de impulsos tanáticos ou eróticos, e como se daria a ligação nesses diferentes aspectos. Parece-nos que a noção de sublimação como vinculação a ideais culturais socialmente valorizados é um tipo de elaboração tipicamente simbólica das demandas pulsionais. É um modelo de produção de um destino pulsional por meio de um processo de verticalização do desejo baseado em identificações edípicas, com a restrição de que esse modelo limita-se a elaborações sublimatórias secundárias. No que tange à dimensão propriamente originária dos processos sublimatórios, o que está em jogo é outra dimensão de ligação, mais propriamente narcísica.

Aqui é que entra em jogo o que talvez seja a maior omissão de Laplanche em seu exame da teoria da sublimação: a segunda concepção freudiana de sublimação. Como se sabe, a partir da segunda tópica e da segunda teoria pulsional, ou seja, no âmbito do último momento de sua obra, Freud (1923/1996) articula a sublimação ao momento de constituição egoica e à fusão pulsional, por meio da noção de dessexualização da pulsão em libido narcísica. Em outras palavras, trata-se de um processo de fusão da pulsão de morte com a pulsão de vida na formação de libido investida no ego, indicando então um mecanismo pulsional para a ligação da dimensão traumática à pulsão de morte. $O$ que Freud não chega a explicitar nessa elaboração teórico-conceitual é que esse processo também está articulado às identificações narcísicas, ou seja, que a ligação em libido - portanto, também a entrada em regimes de simbolização propriamente ditos (representações afetivas e representações de coisa, de palavra e de objeto, nos termos freudianos clássicos), estão articuladas à identificação com o objeto no regime de relações de objeto narcísicas primárias - em suma, à função materna.

O problema é que Freud apenas faz indicações pontuais sobre essa dinâmica, ainda mais porque tanto os conceitos de narcisismo quanto os de pulsão de morte foram pouco explorados na obra freudiana, de forma que a 
própria articulação entre narcisismo e pulsão de morte, que é tão óbvia e fundamental para a metapsicologia, nunca foi levada a termo, como apontaram tantos comentadores (Green, 1988; Rocha, 2000; Campos, no prelo).

As identificações narcísicas são responsáveis não só pela vinculação erótica da unidade do ego por meio do ego ideal/ideal de ego, mas também pela ligação da pulsão de morte em libido. Há, assim, graus de simbolização - ou, se preferirmos, tradução das significações - que estão atrelados a processos identificatórios específicos. Embora sistematicamente ignoradas ou subdimensionadas por Freud, as identificações narcísicas também estão em jogo na produção do laço e da estrutura social. Com exceção do texto clássico sobre a psicologia das massas, em que a identificação é um processo organizador tanto da estrutura do ego quanto dos grupos, Freud discute muito pouco a dimensão narcísica do laço social, já que mesmo nesse momento a identificação é referida majoritariamente à função paterna.

Foi só mais recentemente, em função das discussões em torno do declínio da função paterna na subjetividade contemporânea, que esse caminho de elaboração conceitual foi retomado. É nesse sentido que vieram as indicações de uma função fraterna e de uma identificação horizontal na produção de espaços sociais e psíquicos, como mostraram Birman (1999) e Khel (2000).

Esse é o caminho que a segunda teoria da sublimação em Freud indica, mas Laplanche não dá muita importância a essa concepção. $\mathrm{Na}$ verdade, em nenhum momento ele discute as noções de uma dessexualização das pulsões na formação das instâncias egoica e superegoica, muito menos as articula com mecanismos identificatórios em relação à alteridade ou deriva daí modos de tradução específicos. Parece-nos que aí ele subestima o papel do outro na articulação do destino sublimatório, o que é particularmente frustrante. Com isso ele igualmente reduz a dimensão da cultura na discussão sobre a sublimação.

Entendemos que uma problematização suficientemente abrangente e fundamental sobre o conceito de sublimação deve avançar nesse outro extremo da problemática, incluindo a cultura e a identificação com o outro. Isso também é necessário para dimensionar o lugar da sublimação em uma teorização psicanalítica geral, pois é justamente a concepção de sublimação que deveria ser o fundamento de uma teoria da cultura em psicanálise. Para isso seria necessário também tomar a cultura como campo legítimo da experiência psicanalítica, e não apenas como ilustração de processos psicodinâmicos ou estruturais da subjetividade.

Uma verdadeira psicanálise aplicada deve ser aquela que produza efetivamente uma psicanálise extramuros, âmbito que o próprio Laplanche (1992) define como fundamental na experiência psicanalítica. Uma teorização consequente da sublimação precisa necessariamente incluir essas dimensões. Infelizmente, foi algo que Laplanche não fez nesta sua obra clássica. Resta investigar se em outros momentos o próprio autor ou seus seguidores avançaram em direção a esses questionamentos no âmbito da teoria da sedução generalizada.

\section{CONCLUSÃO}

Este artigo teve como objetivo apresentar e discutir a concepção clássica de Laplanche a respeito da sublimação. Partimos dos paradoxos da concepção de sublimação e das questões que sua caracterização clássica suscita: a modificação da meta e do objeto por meio de um ideal socialmente valorizado. Nessa concepção original o conceito de sublimação fica esvaziado de seu potencial, uma vez que está atrelado exclusivamente a um julgamento de valor sobre a repetição do desejo. O que Laplanche traz de novo nessa discussão é uma relativização da vinculação estreita entre defesa e sublimação, mostrando que, desde Freud, a sublimação se caracteriza por um destino mais independente dos processos defensivos e intrinsicamente criativo.

O problema é que essa criatividade em Laplanche é trabalhada exclusivamente na forma de criação de pulsão em um âmbito originário. Embora possamos entender a riqueza dessa contribuição para mostrar que a sublimação é um processo de constituição de laços psíquicos, falta uma articulação mais ampla dessa dimensão individual com a dimensão propriamente social dos símbolos e parâmetros culturais de verdade, de bem e de beleza. Entendemos que essa articulação só pode ser efetivada por meio de um aprofundamento da discussão sobre os tipos de ligação em jogo na 
sublimação por meio do exame dos processos identificatórios narcísicos em sua relação com a alteridade. A contribuição deste artigo se dá no sentido de indicar esse caminho de investigação e desenvolvimento no âmbito da teoria da sedução generalizada e no campo geral da teoria psicanalítica, na expectativa de que isso possa sugerir um novo paradigma para a constituição e gestão da subjetividade no plano individual e coletivo no contexto da cultura e sociedade contemporâneas.

\section{REFERÊNCIAS}

Birman, J. (1999). Mal-estar na atualidade: a psicanálise e as novas formas de subjetivação. Rio de Janeiro: Civilização Brasileira.

Campos, E. B. V. (no prelo). Limites da representação na metapsicologia freudiana. São Paulo: EDUSP.

Freud, S. (1996). A aquisição e o controle do fogo. (J. Salomão, Trad.). Edição standard brasileira das obras completas de Sigmund Freud (v. 22, pp. 223-233). Rio de Janeiro: Imago. (Original publicado em 1931).

Freud, S. (1996). Leonardo da Vinci e uma lembrança de sua infância. (J. Salomão, Trad.). Edição standard brasileira das obras completas de Sigmund Freud (v. 11, pp. 53-124). Rio de Janeiro: Imago. (Original publicado em 1910).
Freud, S. (1996). O ego e o id. (J. Salomão, Trad.). Edição standard brasileira das obras completas de Sigmund Freud (v. 19, pp. 13-80). Rio de Janeiro: Imago. (Original publicado em 1923).

Green, A. (1988). Narcisismo de vida, narcisismo de morte. Rio de Janeiro: Imago.

Kehl, M. R. (org.). (2000). Função fraterna. Rio de Janeiro: Relume-Dumará.

Laplanche, J. \& Pontalis, J.-B. (1988). Fantasia originária, fantasias das origens, origens da fantasia. Rio de Janeiro: Jorge Zahar.

Laplanche, J. \& Pontalis, J.-B. (1998). Vocabulário da psicanálise (3a ed.). São Paulo: Martins Fontes.

Laplanche, J. (1985). Vida e morte em psicanálise. Porto Alegre: Artes Médicas.

Laplanche, J. (1988). Problemáticas II: castração, simbolizações. São Paulo: Martins Fontes.

Laplanche, J. (1989). Problemáticas III: a sublimação. São Paulo: Martins Fontes.

Laplanche, J. (1992). Novos fundamentos para a psicanálise. São Paulo: Martins Fontes.

Rocha, Z. (2000). Destinos da angústia na psicanálise freudiana. São Paulo: Escuta.

Recebido em 26/07/2012 Aceito em 02/04/2013

Érico Bruno Viana Campos: doutor em Psicologia pelo Instituto de Psicologia da Universidade de São Paulo, professor assistente do Departamento de Psicologia da Universidade Estadual Paulista Julio de Mesquita Filho, Bauru-SP, Brasil. 